\title{
Natural hazard risk in the case of an emergency: the real options' approach
}

\author{
Ludovic Gaudard • Franco Romerio
}

Received: 30 October 2013/Accepted: 21 July 2014/Published online: 2 August 2014

(C) Springer Science+Business Media Dordrecht 2014

\begin{abstract}
In the case of an emergency provoked by a natural event, decision makers should (1) acquire a comprehensive understanding of the current dynamics and (2) take the optimal decision based on the information available at that moment. Scientists should provide the key inputs to decision makers, as well as clearly highlight the current dynamics. While much progress has been made in this field, the theory of options, which was developed to assess financial and real investments in an uncertain world, has as yet never been applied in emergency management related to natural hazards. This article highlights, through some simple examples, the contribution that this approach may provide in this field. First, it allows the comparison of different strategies and to value their degrees of flexibility. Second, it allows the determination of the optimal timing of different types of intervention. Finally, thanks to decision trees, this approach provides a clear and concise presentation of the current dynamics. Options theory possesses an interesting potential to improve emergency management.
\end{abstract}

Keywords Natural hazards · Real options · Emergency management $\cdot$ Cost-benefit analysis

\section{Introduction}

The use of scientific knowledge by decision makers is topical. This issue is of even greater importance in the context of natural hazards (Habib and Nokra 2004). In fact, the risk is generally high in spite of the fact that the probability of occurrence of big events is low. It

L. Gaudard ( ()

Institute for Environmental Sciences, University of Geneva, Geneva, Switzerland

e-mail: ludovic.gaudard@unige.ch

F. Romerio

Geneva School of Economics and Management, Institute for Environmental Sciences, University of Geneva, Geneva, Switzerland 
represents the classic "black swan" problem (Makridakis and Taleb 2009). The decision to evacuate an area at risk is complex, and the best techniques available should be applied in order to make choices as effectively and efficiently as possible. In this article, we propose to add another tool to the bag by integrating the options theory approach in the context of natural hazards.

The options theory, usually applied in the assessment of real and financial investments, is first of all a "reasoning framework" (Mun 2010). The application of this approach in the field of natural hazards should highlight the different options available during an emergency. Furthermore, the decision trees, with their decision and chance nodes, which are presented in this paper, should improve communication to decision makers and stakeholders. Options theory has already been applied in the field of natural hazards but not specifically in emergency management.

In this article, we point out the added value that options theory can provide in comparison and addition to traditional methods. Cost-benefit analysis (CBA), which is sometimes applied to assess the consequences of an evacuation, may be combined with options theory to evaluate a broad set of options, when the information availability evolves during the time of emergency. Among other things, this approach assigns a value to flexibility.

This article represents a first step toward the development of a complementary approach that can improve emergency management. It provides an accessible presentation of real options theory in the context of natural hazards. The similarities of the hypotheses and methods applied in natural hazard management and in real options theory should facilitate the convergence between these two approaches. Relevant contributions should be expected in this field in the near future.

The article is organized as follows: Sect. 2 provides some basic concepts about risk management, CBA and its relevance in the case of an emergency. Section 3 presents the options theory and its applications. The current state of the literature is quoted in these two sections. Section 4, devoted to emergency management and real options, represents the core of the article. It includes several hypothetical examples illustrated with decision trees. Section 5 presents a more complex example about a volcanic eruption, although options theory can be applied to the entire spectrum of natural hazards. The discussion of the results is given in Sect. 6. The conclusion follows.

\section{Risk management}

Various models and criteria have been developed to assist decision makers in the field of risk management. First of all, uncertainty should be distinguished from risk. The latter "refers to a situation in which the potential outcomes can be described in objectively known probability distributions," whereas in the case of uncertainty, "no reasonable probabilities can be assigned to the potential outcomes" (Haimes 2004, p. 227). In the case of uncertainty, one can apply different decision criteria, called maximin, maximax, etc. (Arrow 1951; Luce and Raiffa 1957). For instance, in the case of the "minimax regret," one looks at the maximum regret associated with each state of the nature and chooses the option with the smallest regret.

As far as it is possible to assess the probability of occurrence of an event, the decision can be taken on the basis of an "expected value." Usually, a trade-off is made between expected costs and expected benefits related to the realization of different protective measures (Kunreuther 1996). In general, benefits represent avoided costs. 
However, since the eighteenth century, thanks to Bernoulli, we know that in principle decisions are not determined by the expected value. The individual's attitude toward risk plays an important role. In fact, the expected utility theory shows that if individuals are riskaverse, they accept to pay a certain amount of money (for instance, by buying an insurance policy) in order to avoid an unwanted outcome (Hey 1979; Luce and Raiffa 1957).

The prospect theory shows that the problem is even more complex (Kahneman and Tversky 1979). There are asymmetries between potential gains and potential losses. The utility associated to a gain is lower than the disutility associated to a loss. The utility/ disutility decreases as the gains/losses are increased. Furthermore, probabilities may be over or underestimated. Both prospect theory and expected utility theory show that the expected value does not necessarily explain the decision taken by decision makers, and lay people and even experts.

A discussion of the limits of the expected utility theory and the relevance of prospect theory for natural hazards and disaster management is provided by Asgary and Levy (2009). Eiser et al. (2012) review the literature devoted to risk interpretation and its implications for action. By quoting ICSU (2008), they stress that "the seriousness of the consequences of any disaster will depend also on how many people choose, or feel they have no choice but, to live and work in areas at higher risky..." (p. 6).

In this article, we present another approach. We take stock of the literature on expected value as well as on CBA, but we propose some developments based on the options theory. CBA literature is briefly summarized below. Options theory will be introduced in Sect. 3.

\subsection{Cost-benefit analysis (CBA)}

CBA (De Rus 2010) is often applied in natural hazard risk management, because it represents a comprehensive assessment of the social costs and benefits related to a decision of implementing a plan of evacuation (Gamper et al. 2006). In this perspective, the cost of an evacuation should include the private costs (transportation, rehousing, loss of revenue in the evacuated region, etc.), as well as the negative externalities (for instance, loss of social relations due to displacement). It is the same for benefits, for instance, through the inclusion of avoided human losses. The main challenge is to assign a price to externalities.

The case of the price of life is particularly relevant, although controversial (Cropper and Sahin 2009). There are two main approaches to estimate it. Under the "human capital" approach, the price of life is determined by the lost earning potential of the victim. The alternative one is based on peoples' "willingness to pay" (WTP) for higher safety. While both methods have their own flaws, the WTP approach produces higher values and tends to be preferred.

One should note that the cost and benefits should be discounted as far as they appear in different periods of time, in order to obtain the present value of a plan of intervention or project of investment (for instance shelters) in risk mitigation (cf. Eq. 1). In the CBA, the "social rate of discount" should be applied (Marglin 1963). The discount rate itself could be affected by extreme events (Ermoliev et al. 2010). In principle, even the future value of the lives saved is discounted. We do not discuss these issues, which are the subject of a huge amount of the literature, but we can assume that in the examples below the costs and benefits are discounted.

$$
N P V=\sum_{t=0}^{T} \frac{B_{t}-C_{t}}{(1+r)^{t}}
$$


where NPV is the net present value, $\mathrm{B}_{\mathrm{t}}$ the benefit at time $t, C_{t}$ the cost at time $t$ and the rate of discount is $r .(1+\mathrm{r})^{\mathrm{t}}$ is the discount factor.

\subsection{Management during emergencies}

Marzocchi and Woo (2007) discuss the "scientific management of volcanic crises" and focus on the expected value criteria. In the case of an emergency, they conclude that evacuation should be carried out if:

$$
p>\frac{C}{L}
$$

where $p$ is the probability of occurrence of an event, $C$ is the cost of the protection measures and $L$ represents the potential losses if no protection measures are deployed. $L$ includes in particular the human losses. $C$ and $L$ should be discounted if they arise over different time periods.

These decision criteria may be relevant as far as decision makers have to deal with «now-or-never » situations. This means that if they decide not to deploy protection measures, they will not be able to do it later. But, if one is not in a "now-or-never" situation and information changes over time, this criterion is not optimal. In fact, information has a value, which may be important when uncertainties are high (Katz and Murphy 1990). Equation 2 does not allow for taking into consideration the information improvements, as well as adopting a flexible approach in risk management. These drawbacks may be overcome by the options theory, whose historical background we now briefly sketched by focusing on the most relevant aspects for natural hazard.

\section{Options}

The principle of options theory is quite simple: One should consider the options available at each point in time and focus on flexibility. The strategy should be adapted to the uncertainty's evolution. When a decision that has irreversible effects is taken, an option is exercised. The lost option entails a cost because flexibility possesses a value. This cost should be taken into consideration in the assessment of the actions that can be undertaken. If it is forgotten, the theory fails in explaining the decision makers' behavior. In other words, real options theory is de facto intuitively applied in the real world (Pindyck 1991).

As already pointed out, options theory has been applied in the field of natural hazard and risk mitigation. In this respect, one should quote Hatori et al. (2004), who studied the social learning processes in relation to the mitigation of an earthquake's impact; Mondello (2007), who discussed investments in built-up areas exposed to a tsunami risk in the light of the precautionary principle and investment in building in the context of a Tsunami; Eladaway (2012), who assessed the real option implications in the case of windstorms. Options theory has also been applied in the field of industrial hazards (Reniers et al. 2011; $\mathrm{Yu}$ and Chen 2011). However, options theory in emergency management linked to natural hazard has not been considered.

\subsection{Financial options}

Options theory emerged in the field of finance and provides a number of financial products (Black and Scholes 1973). For instance, it allows a buyer to hedge the risk that the price of 
the good he seeks to acquire may rise sharply before its purchase (call option). The parallel exists for the sellers in order to protect them against a falling market (put option).

Before going into further details, it is useful to provide some definitions. An option is characterized by different parameters.

- Underlying asset: the option's good (for instance, oil)

- Strike price: the price, defined by the option, to which the asset can be exchanged

- Option life: the option's lifetime

In the case of a call option, the buyer wants to purchase an asset (e.g., a barrel of oil) at some point in the future (e.g., in 1 year). If he does not want to hedge the risk, he can wait and pay the market price at that point. Otherwise, he can buy an option that gives the right, but not the obligation, to purchase the asset at the strike price (for instance, he can buy an oil barrel at 100 US\$). One should point out that in the case of a "European option," the purchase must be completed at a certain instant (say, in exactly 1-year time), whereas in the case of an "American option," the purchase can be made throughout the option life.

For simplicity's sake, we take into consideration the case of the European call option. On the due date, the person who possesses the option would face one of the following situations:

- The market price of the underlying asset is lower than the strike price. The option has no value. His owner has lost the option cost.

- In the opposite case, the option value is given by the difference between the market price and the strike price.

Thus, as shown by Fig. 1, the option value at maturity (Brach 2003) is:

$$
V_{c}=\max \left(P-S_{p}, 0\right)
$$

where $V_{c}$ is the value of the call option, $P$ is the market price of the underlying asset and $S_{p}$ is the strike price.

The option's purchase is only profitable if the market price is higher than the neutral. One should note that the buyer's potential loss is limited whereas the seller's one may be infinite. In fact, the call options reduce the buyer's risk, which, however, has to be paid through a premium, i.e., the option's initial cost.

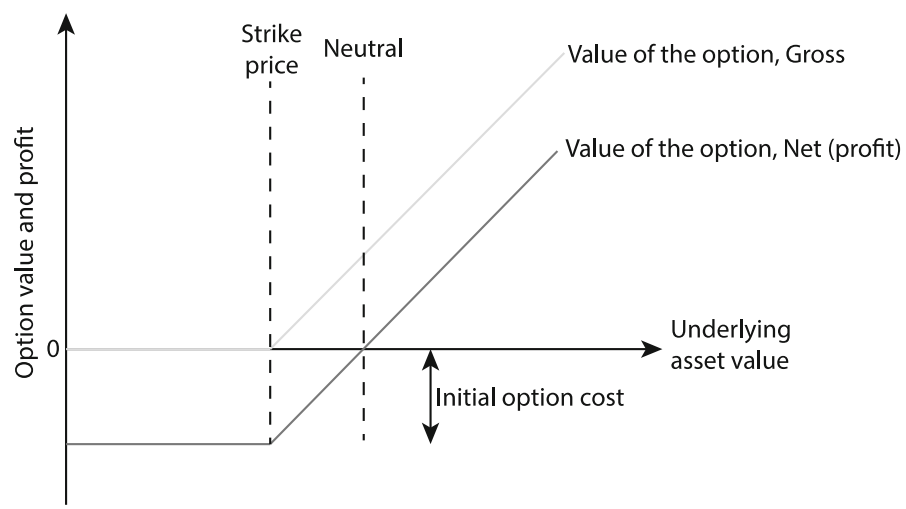

Fig. 1 Option's value and profit in relation to the value of the underlying asset (based on Kodukula and Papudesu (2006)) 
Several models were developed to estimate the option's value at the time of purchase. The most common are the Black-Scholes model for the European options in continuous time (Black and Scholes 1973), as well as the discrete time binomial approach proposed by Cox, Ross and Rubinstein (Cox et al. 1979). These models are relevant as far as the risk premium varies with the underlying asset course.

\subsection{Real options and other developments}

The options theory was subsequently applied to assess investment projects in different fields, including infrastructure (transportation, energy supply, etc.) (Dixit and Pindyck 1994). The term "real options theory" is used in these regards, and the approach is similar to that used in finance.

In this perspective, one should interpret the alternatives of a project of investment as options. If a decision maker decides to engage himself in a process of evaluation of a new product, he keeps open the option of abandoning this kind of investment if it is not profitable. While the evaluation is available, he can decide to pursue or abandon the project. In certain cases, going ahead means not being able to stop it in the future, in which case the "option is killed."

In this example, the strike price is the cost of the investment if one supposes that there are no other costs that have to be supported in the future; the option's initial cost is the cost of the evaluation phase; the value of the underlying asset is the revenue generated by the investment.

The possible link between the "real option approach" and the "principle of precaution" was highlighted by Gollier and Treich (2003), who showed that flexibility has a big value from a social point of view. The fact of keeping alive an option may allow taking advantage of new information that should be available in the near future. Furthermore, undesirable irreversibility can be avoided.

In the next section, we will point out how the real options theory may be applied to the field of natural hazard emergency. The options open to decision makers during an emergency may be interpreted as investment projects. The intuitive approach of decision trees is the most appropriate in this respect. One should carry out several steps to build a decision tree in the framework of the real options theory, as we will show in detail in the next section:

1. Definition of the risk and available options;

2. Determination of the inputs' value;

3. Construction of the decision tree;

4. Estimation of the options' value through a process of back-casting;

5. Analysis of the results.

\section{Emergency management and real options}

\subsection{Risk identification and options available}

A nonexhaustive list of the most common options available is provided below. They are particularly relevant in the case of natural hazard risk management.

- "To wait, to delay": This is very useful when information evolves; in this case, one can take advantage of a «learning option » because during the waiting time, some uncertainties may be cleared. 
- "To expand": For instance, the ability to expand an evacuation plan from local to regional level.

- "To contract": the opposite of the previous option; one can imagine that in an evacuation plan that includes different steps, it is possible to come back to previous steps if the situation improves.

- "To abandon": For instance, the ability to remove the state of emergency if the situation returns to normal, as we will see later.

- "To choose": Being able to choose between different strategies.

- "Parallel compound": Different options bonded to each other. In the case of an exclusive choice between various strategies, taking an option means killing all the others.

- "To stage": The evacuation plan should be carried out step-by-step according to the dynamic of the event. First, one should launch the advanced monitoring; then, the zone at highest risk should be evacuated. Finally, the evacuation should be extended to the whole region.

This approach is very important for both the analytical and the decision-making process. In fact, decision makers are able to clarify the decisions that should be taken thanks to the definition of the available options. One should not lose sight of the fact that the identification of the whole set of options is a big step forward.

\subsection{Determination of the parameters}

The option's parameters should be determined in order to compute its value. In the case of a natural hazard, one can accept that the value of the underlying asset is the cost provoked by the event if no intervention is implemented. The strike price is the cost brought about by the event if the intervention is implemented, i.e., the unavoidable cost. To simplify, we suppose that the option's cost is represented by the declaration of a state of emergency. The option lasts as long as the task force remains in place.

Such an option is an American one, which may even have an infinite life. It is used if the intervention is ordered and killed if the state of emergency is removed. Costs should be evaluated on the basis of a cost-benefit analysis.

The comparison between the examples discussed above is presented in the Table 1 .

\subsection{Decision tree}

As already mentioned, decision tree provides a self-explanatory illustration of the real options' approach in such a case. A decision tree includes three types of nodes. The

Table 1 Comparison between three examples of options theory's application

\begin{tabular}{|c|c|c|c|}
\hline & Trading & Investment & Natural hazard \\
\hline $\begin{array}{l}\text { Value of the } \\
\text { underlying asset } \\
(P)\end{array}$ & $\begin{array}{l}\text { Market price of the oil } \\
\text { barrel }\end{array}$ & $\begin{array}{l}\text { Expected revenue generated } \\
\text { by the investment }\end{array}$ & $\begin{array}{l}\text { Expected cost of the event } \\
\text { if no intervention }\end{array}$ \\
\hline Strike price $\left(S_{p}\right)$ & $\begin{array}{l}\text { Fixed price negotiated } \\
\text { in the contract }\end{array}$ & Investment cost & $\begin{array}{l}\text { Expected cost if } \\
\text { intervention }\end{array}$ \\
\hline Option value & $\max \left(P-S_{p}, 0\right)$ & & \\
\hline Initial option price & $\begin{array}{l}\text { Price paid at time } 0 \text { to } \\
\text { get the option }\end{array}$ & Cost of evaluation & $\begin{array}{l}\text { Cost of being in a state of } \\
\text { emergency }\end{array}$ \\
\hline
\end{tabular}


decision nodes represent the points where the decision makers should choose between different strategies; in particular, they can decide to keep or to kill the option. The chance nodes show different random events. Here, there is no decision to be taken, but probabilities of occurrence to be explored. The end nodes indicate the final issues. Starting from the latter, one can compute the value of an option at each node through a back-casting approach.

The advantage of this approach does not differ substantially from the event tree and fault tree analysis, which is among the key tools used in hazard and risk assessment (Newhall and Hoblitt 2002). The integration between these tools and the options theory does not raise any major difficulty. The difference lies in the fact that decisions represent an essential part of the analysis in the options theory. On the contrary, the traditional tools of analysis focus exclusively on natural hazards; the event and fault trees do not take into consideration the decisional process, i.e., decision nodes.

Figure 2 shows an example of a decision tree in the case of a "now-or-never" evacuation. Throughout this article, decision nodes are represented by squares, whereas chance nodes by circles. Above the chance nodes, a sum is indicated: The number on the left represents the cost incurred by the decision taken upstream; the number on the right represents the expected costs downstream. Costs are expressed in millions of US\$ (M\$). In this case, if the evacuation takes place, there is no damage but it costs $3 \mathrm{M} \$$. In the opposite case, the losses are $10 \mathrm{M} \$$. The probability that an event occurs is $45 \%$. Because there is no intervention cost in this second situation, the expected loss is $4.5 \mathrm{M} \$$ $(0.45 * 10+0.55 * 0)$. The best choice is evacuation as we presume that the goal is to minimize expected costs.

The criterion of Eq. 2 gives the same result, e.g., one should act immediately. In fact, the following inequality satisfies the evacuation criterion:

$$
\frac{C}{L}=\frac{3}{10}=0.3<P_{\text {eve }}
$$

In this case, there is no difference between the two criteria. The inflexibility in the management explains this similarity. In such a context, the added value of the real options theory is nil. This is not the case in the examples that follow.

\subsection{The option value}

We now present two simple examples of the evaluation of the option's value, notably the « defer » option and the « stage » one. Thereafter, we will combine them to highlight a « choose » option, which is more complex.

But first, the evacuation can be seen as an option. Equation 3 shows that in the previous example (Fig. 2), its value is

$$
\begin{aligned}
V_{\text {eva }} & =\max \left(P-S_{p}, 0\right) \\
& =\max (\text { Expected cost of the event if no intervention-expected cost if intervention, } 0) \\
& =\max (4.5-3,0)=1.5
\end{aligned}
$$

This means that killing this option has a cost of $1.5 \mathrm{M} \$$. If the cost provoked by the state of emergency is higher, one should abandon it. The contrary if the cost is lower. 


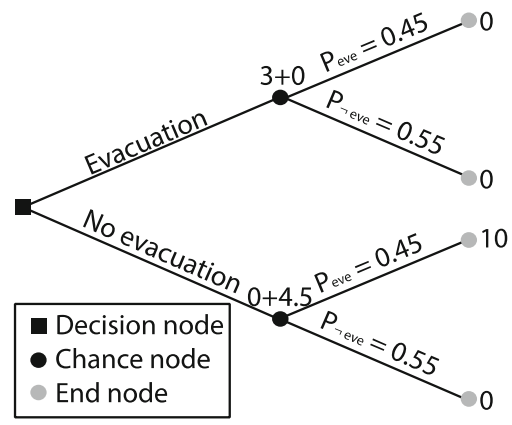

Fig. 2 Decision tree for an evacuation

Now, we should suppose that the event can be sequenced in two stages (Fig. 3). We assume that the probability to move to a higher warning level is $50 \%$. In this case, the probability of occurrence of the event is $90 \%$. In the opposite case, one goes back to normality and the probability of the event is zero for the period taken into consideration. One should notice that at time $t=0$, the probabilities are the same as in the previous example, i.e., $P_{\text {event }}=0.9 * 0.5=0.45$ and $P_{\text {no event }}=1-P_{\text {event }}=0.55$. The difference lies in the fact that the event is sequenced. Concerning costs, the difference from the previous example stems from the fact that if the evacuation is ordered only in the second phase, and the event occurs, losses are $1 \mathrm{M} \$$ instead of zero.

Figure 4 represents this example with expected costs and options values. Starting from the right side of the decision tree, the expected loss is $\mathrm{M} \$ 0.9 * 1+0.1 * 0=0.9$ if the evacuation is ordered at time $t=1$ (upper right chance node). The total cost, evacuation included, will be $\mathrm{M} \$ 3+0.9=3.9$. In the opposite case (lower right chance node), there is no evacuation. The expected loss is $\mathrm{M} \$ 10 * 0.9+0 * 0.1=9$. Going back upstream (left chance node), taking into consideration the option of waiting, we notice that the cost is zero but the expected loss is $\mathrm{M} \$ 0.5 * 3.9+0.5 * 0=1.95$. The value of the "waiting" option is the following:

$$
\begin{aligned}
V_{\text {wait }} & =\max \left(P-S_{p}, 0\right) \\
& =\max (\text { Expected cost of the event if no intervention-expected cost if waiting, } 0) \\
& =\max (4.5-1.95,0)=2.55
\end{aligned}
$$

$V_{\text {wait }}$ is then positive, like in the case of the evacuation option. One should point out that at the first node, the "waiting" option represents the one that has the largest value. Because

Fig. 3 Probability of an event

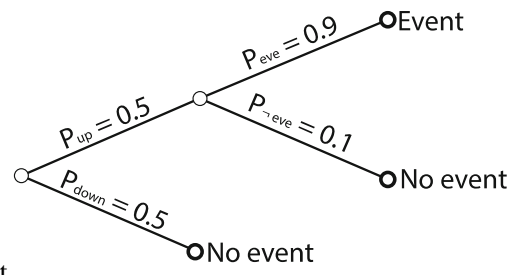




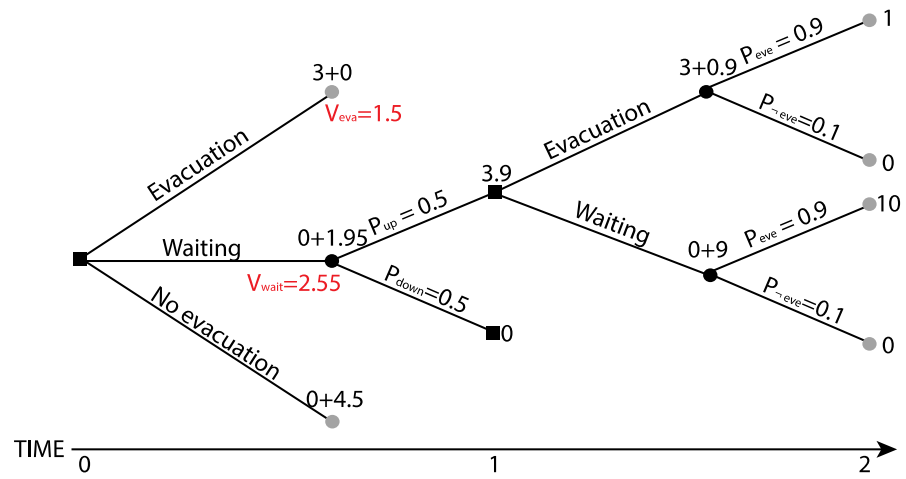

Fig. 4 Decision tree for the waiting option with expected costs and options values

engaging in an evacuation kills the waiting option, one should wait that more information will be available, although there are some potential losses at the end. In the case of continuous time, the option to wait should be killed when its value is lower than that to evacuate. One acts if the outcome is better than doing nothing.

Furthermore, by adding the "waiting" option, there is an increase in the value of declaring the state of emergency. In fact, the emergency not only keeps open the "evacuation" option, but also the "waiting" option, which possesses a higher value. Thus, the state of emergency's cost can reach $2.55 \mathrm{M} \$$, i.e., the value of the waiting's option. In other words, the fact of keeping alive the waiting's option increases the gain of creating a system allowing future interventions.

We now present a «stage » option. One supposes that it is possible to immediately evacuate the most dangerous zones at the cost of $1 \mathrm{M} \$$. If the level of emergency is higher, the evacuation can be extended to the entire region at risk at a cost of $2.5 \mathrm{M} \$$. In this case, there will be no losses. On the contrary, if the event occurs when the level of emergency is low, the losses will be $6 \mathrm{M} \$$. The question is therefore whether this option is more advantageous.

The value of the stage option is

$$
\begin{aligned}
S_{p} & =1+(0.5 * 2.5+0.5 * 0)=2.25 \\
V_{\text {stage }} & =\max \left(P-S_{p}, 0\right)=\max (4.5-2.25,0)=2.25
\end{aligned}
$$

As it is positive, one should adopt this approach rather than doing nothing. However, this value is lower than simply waiting. The two options being exclusive, one should choose between stage and waiting. Killing the waiting option is more expensive. Thus, one should keep it alive (Fig. 5).

\section{Application to an hypothetical case: a volcano eruption}

To show the practical relevance of the options theory, we provide a more complete example. The case of a volcanic activity is particularly relevant. In fact, in most cases, thanks to the time gap between the first precursors and the eruption, the emergency management may take advantage of a certain degree of flexibility. Furthermore, it is possible to acquire new information as time elapses. One should stress that the economical analysis should be directly incorporated into the tree. In fact, most of the time, it is carried 


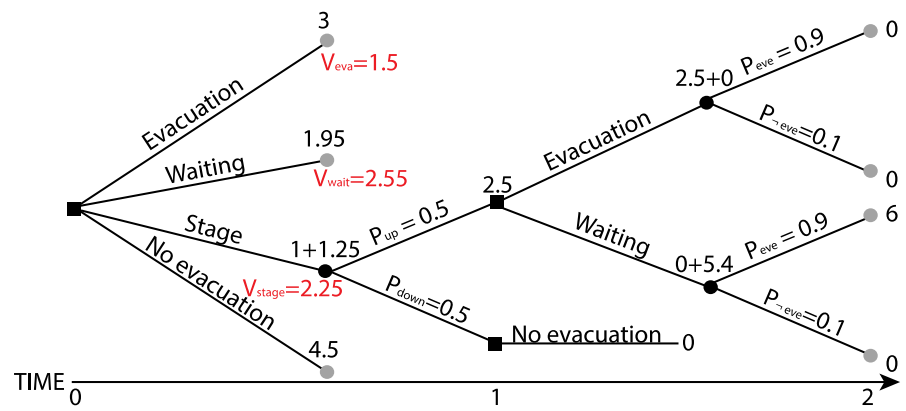

Fig. 5 Stage option

out only subsequently, by taking into consideration the probabilities of occurrence and by analyzing various options separately (Van Stiphout et al. 2010).

The following is a hypothetical case. At time $t=0$, the volcano enters in a phase of unrest. At each time increment, the probability of passing to a higher level of activity is $20 \%$ and to a lower level $80 \%$. One stops the simulation at time $T=3$ where a choice should be made concerning the evacuation. One supposes that there are damages only if the activity reaches level E. Figure 6 represents the case under review. At each node, the probability of reaching level A or E is indicated, respectively, below and above the node.

One supposes that the time increments 1,2 , etc., correspond to a new decision makers' meeting. At no time, does the volcano stay at the same level of activity. This would be quite easily represented in the decision tree by adding chance nodes between meetings. To approach a continuous time, one should add decision nodes. In this case, one has to adapt probabilities as well as changes. For the sake of clarity, we therefore ignore additional nodes in our example.

Decision makers have the choice between three strategies, which are similar to those presented in Sect. 4:

Fig. 6 The black data represent the probability of going up and down in the levels of activity. In gray, the probability of an eruption (above) and the probability of coming back to a situation of rest (below)

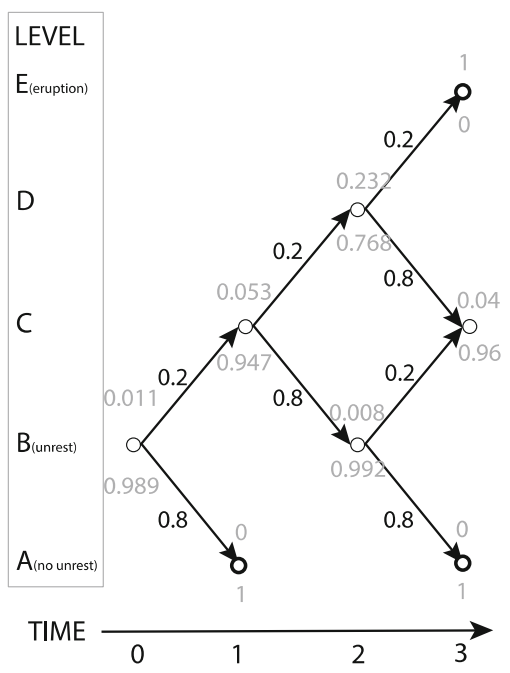


- Not to evacuate, but waiting.

- To order a first evacuation phase, which retains flexibility as it can easily be canceled and re-activated. Its cost is also lower than a total evacuation. In the case of a high level of emergency, the latter can be ordered more quickly.

- To order the total evacuation of the region at risk, this can be done only once. The population will not be able to come back before the situation becomes quiet and stable.

Figure 7 represents the choices that can be done at each decision-node.

One supposes the following costs (Table 2):

Figure 8 shows the decision tree. The complexity is due to the fact that there are many options, as well as many chance and decision nodes. On the right, costs are assessed on the basis of a back-casting approach. The end nodes indicate either evacuation or the extremes of the volcano's evolution, i.e., rest or eruption.

Once the analysis is carried out, relatively few options remain. The optimal path is the one drawn in bold in Fig. 8. The best choice gives rise to a single branch, while the probabilities' nodes open multiple paths. The decision tree can thus be summarized by Fig. 9, which allows decision makers and stakeholders to focus on the most important results of the analysis.

It is apparent from this example that the evacuation's option is only taken when level D is reached. The stage's option is never applied due to hypotheses made in the example, which was quite simplified.

Finally, Table 3 shows the situations in which real option analysis provides an important added value in comparison to classical analyses. Since, often in reality, risk and flexibility are high, options theory deserves careful attention by experts as well as by decision makers. Moreover, practical applications will enrich the conceptual framework itself.

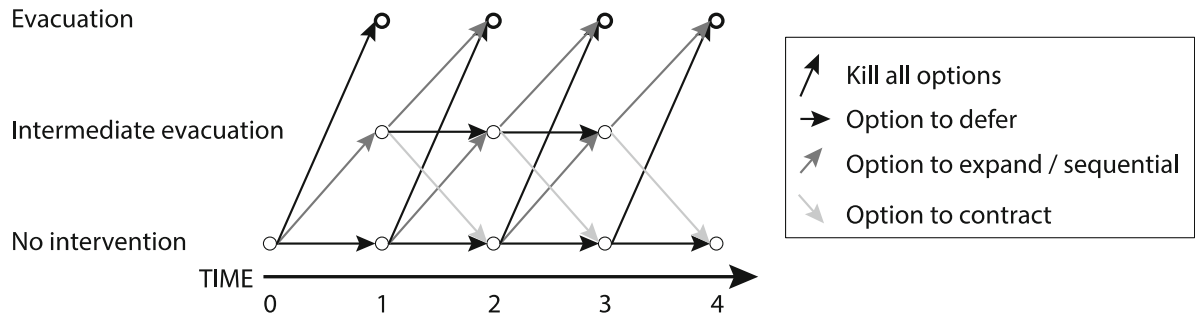

Fig. 7 Options available at each time increment depending on the stage of emergency

Table 2 Costs of intervention and eruption depending on the stage of emergency

\begin{tabular}{lllr}
\hline Cost of intervention & \multicolumn{3}{c}{ Cost if eruption } \\
\hline State $0-1$ & 1 & State 0 & 100 \\
State $0-2$ & 5 & State 1 & 50 \\
State $1-2$ & 5 & State 2 & 0 \\
State $1-0$ & 0 & & \\
\hline
\end{tabular}



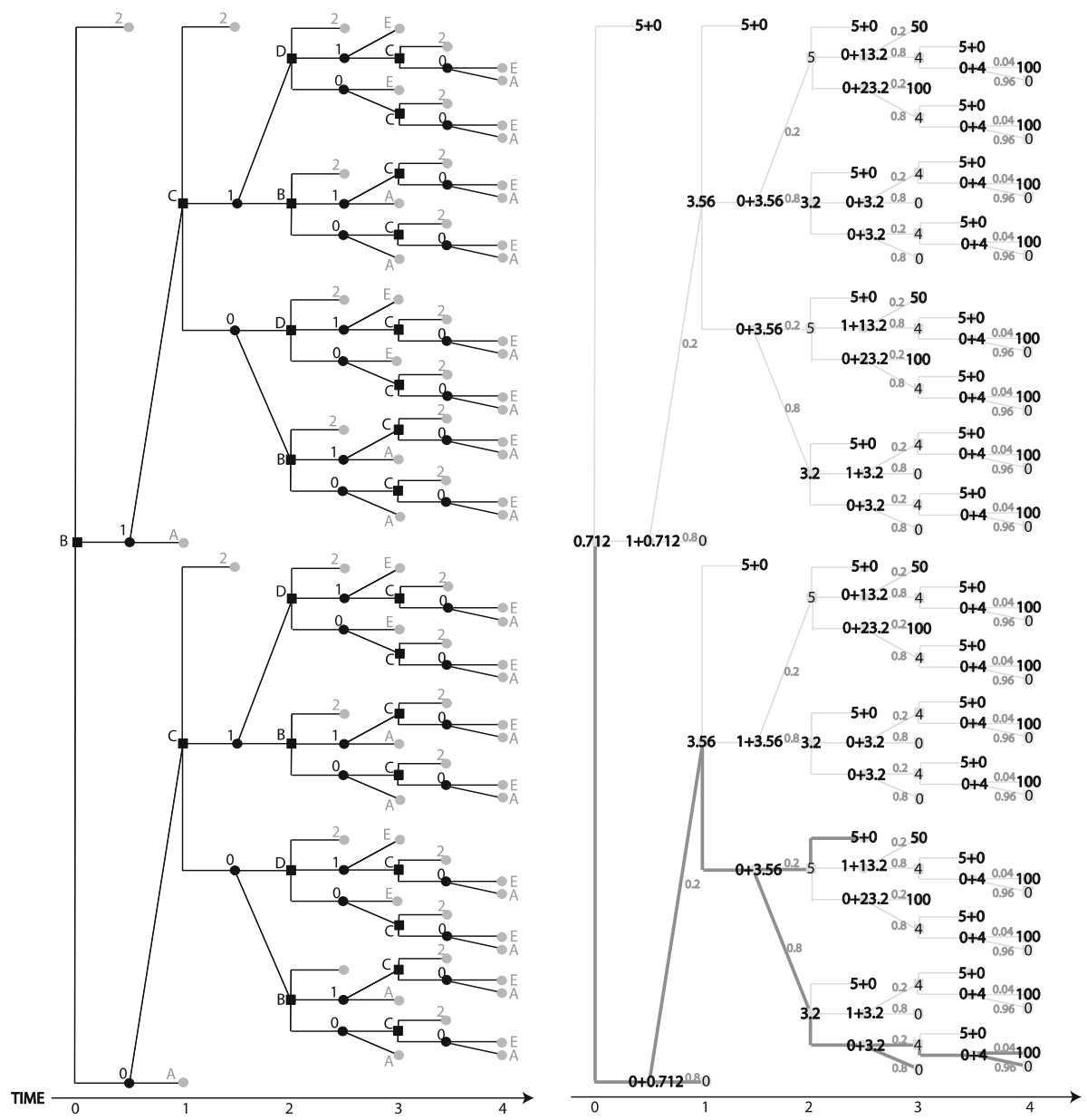

Fig. 8 Figures indicate the protection level: 0 if there is no protection, 1 for an intermediate level and 2 for the evacuation. Letters indicate the volcano's activity. On the left, the graph shows the stages of emergency and the level of volcano activities; on the right, the costs and the choices made, using a back-casting approach

Fig. 9 Sum up of Fig. 8 by considering that optimal choice was made at each decision nodes

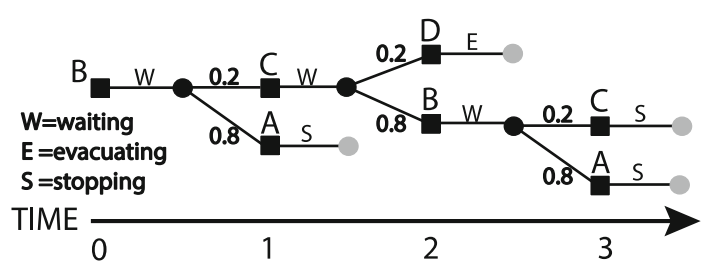

\section{Discussion}

The options theory offers a "reasoning framework" to planners and experts and facilitates the communication with decision makers and stakeholders. It does not represent the 
Table 3 Contribution of real options depending on the level of flexibility and risk (based on Kodukula and Papudesu (2006))

\begin{tabular}{lll}
\hline Flexibility & Risk & \\
\cline { 2 - 3 } & Low & High \\
\hline High & Medium & High \\
Low & No added value & Small \\
\hline
\end{tabular}

panacea to solve all the complex problems linked to an emergency, but it allows the exploration of the options available at each point in time, taking advantage of flexibility. The decision tree, with its decision and chance nodes, represents in itself an important achievement. Both chance and decision nodes should be highlighted by natural and social scientists alike.

This approach represents a progress with respect to the expected value criteria (Eq. 2) whenever decision makers do not face a "now-or-never" situation and information changes over time. The definition of an optimal path may significantly facilitate the decisional process. All the options are in fact ranked, quantified and the most effective selected. In principle, the relevant costs and benefits (avoided costs) can be assessed through a standard CBA approach.

The options theory may be viewed as a normative as well descriptive approach. It is normative, because the goal is to provide guidelines on how to make decisions. Descriptive as far as one supposes that the decision makers, thanks to their cognitive abilities, spontaneously apply the options theory. It is in fact at the crossroads between a normative and descriptive approach that empirical studies on emergency management should explore the theory.

The objective of such a tool is to assist the decisions makers, not to dictate a solution. In fact, in the real life cases, for instance, when the social and economic costs of an evacuation are very high and the likelihood of false alarm is not negligible, other factors must be taken into account, including political turmoil and the pressure by the media. Moreover, the prospect theory has shown the importance of the psychological aspects, as pointed out in Sect. 2.

Furthermore, the options theory remains anchored in the field of finance, and its applications to natural risks are still in its infancy. The dissimilarities between financial and natural risks (for instance, the stakeholders involved) are no less important than the similarities (for instance, domino effects). One should also consider that CBA is still jeopardized by the difficulties in monetizing the external costs and the price of life.

Nonetheless, options theory provides a fresh perspective of the emergency management problem, and its potential warrants careful investigation.

\section{Conclusion}

This article shows that options theory may provide a valuable contribution to natural hazard risk management, in particular during emergencies when an evacuation is envisaged. Applied to the classical CBA method, this approach enables experts and decision makers to take advantage of the flexibility usually offered by the real world. Its advantage lies in its ability (1) to highlight the available options and to clearly present them to the decision makers and stakeholders, and (2) to compare and select the options, as well as to optimize decision time.

The examples provided in this article should be further developed through empirical studies. Many problems and scenarios belonging to the realm of possibility in the field of 
natural hazards should be considered. One important requirement, as shown in the examples above, is to carry out the physical and economical analysis in parallel and to represent it by means of decision trees.

Acknowledgments The authors would like to thank two anonymous reviewers for their insightful advice and enriching comments. We are grateful to Dr. Margot Hill and Mr. Luke Gueriane for proofreading an earlier version of the paper.

\section{References}

Arrow KJ (1951) Alternative approaches to the theory of choice in risk-taking situations. Econometrica 19:404-437

Asgary A, Levy J (2009) A review of the implications of prospect theory for natural hazards and disaster planning. Int J Environ Res 3:379-394

Black F, Scholes M (1973) Pricing of options and corporate liabilities. J Polit Econ 81:637-654. doi:10. $1086 / 260062$

Brach MA (2003) Real options in practice. Wiley finance. John Wiley \& Sons, Hoboken

Cox JC, Ross SA, Rubinstein M (1979) Option pricing: simplified approach. J Financ Econ 7:229-263. doi:10.1016/0304-405x(79)90015-1

Cropper ML, Sahin S (2009) Valuing mortality and morbidity in the context of disaster risks. The World Bank, Washington

De Rus G (2010) Introduction to cost-benefit analysis: looking for reasonable shortcuts. Edward Elgar Publishing Ltd, Cheltenham, UK and Northampton

Dixit A, Pindyck R (1994) Investment under uncertainty. Princeton University Press, Princeton

Eiser JR et al (2012) Risk interpretation and action: a conceptual framework for responses to natural hazards. Int J Disaster Risk Reduct 1:5-16. doi:10.1016/j.ijdrr.2012.05.002

El-adaway I (2012) Insurance pricing for windstorm-susceptible developments: bootstrapping approach. J Manag Eng 28:96-103

Ermoliev Y, Ermolieva T, Fisher F, Makowski M (2010) Extreme events, discounting and stochastic optimization. Ann Oper Res 177:9-19. doi:10.1007/s10479-009-0606-4

Gamper CD, Thoni M, Weck-Hannemann H (2006) A conceptual approach to the use of cost benefit and multi criteria analysis in natural hazard management. Nat Hazard Earth Syst Sci 6:293-302

Gollier C, Treich N (2003) Decision-making under scientific uncertainty: the economics of the precautionary principle. J Risk Uncertain 27:77-103. doi:10.1023/a:1025576823096

Habib S, Nokra NA (2004) Transferring knowledge from observations and models to decision makers: an overview and challenges. Proc SPIE Int Soc Opt Eng 5234:738-743. doi:10.1117/12.513892

Haimes YY (2004) Risk modeling, assessment and management, 2nd edn. Wiley, Hoboken, New Jersey

Hatori T, Matsushima K, Kobayashi K (2004) Providing disaster information and motivation for mitigation. In: IEEE international conference on systems, man and cybernetics, pp 1050-1055. doi:10.1109/ ICSMC.2004.1398443

Hey JD (1979) Uncertainty in microeconomics. Martin Robertson and New York University Press, New York

ICSU (2008) A science plan for integrated research on disaster risk: addressing the challenge of natural and human-induced environmental hazards. International Council for Science, Paris

Kahneman D, Tversky A (1979) Prospect theory: an analysis of decision under risk. Econometrica 47:263-291

Katz RW, Murphy AH (1990) Quality value relationships for imperfect weather forecasts in a prototype multistage decision-making model. J Forecast 9:75-86. doi:10.1002/for.3980090107

Kodukula P, Papudesu C (2006) Project valuation using real options. J. Ross Publishing, Fort Lauderdale, Florida, USA

Kunreuther H (1996) Mitigating disaster losses through insurance. J Risk Uncertain 12:171-187

Luce RD, Raiffa H (1957) Games and decisions. John Wiley, New York

Makridakis S, Taleb N (2009) Decision making and planning under low levels of predictability Introduction. Int J Forecast 25:716-733. doi:10.1016/j.ijforecast.2009.05.013

Marglin SA (1963) The social rate of discount and the optimal rate of investment. Quart J Econ 77:95-111. doi:10.2307/1879374

Marzocchi W, Woo G (2007) Probabilistic eruption forecasting and the call for an evacuation. Geophys Res Lett 34 doi:10.1029/2007g1031922 
Mondello G (2007) Methodological economic assessment of Tsunamis impact in the Mediterranean area. Paper presented at the ENCORA Project, Venice

Mun J (2010) Real options in practice. In: Nembhard HB, Aktan M (eds) Real options in engineering design, operations, and management. CRC Press, Taylor \& Francis Group, Boca Raton, USA, pp 7-13

Newhall CG, Hoblitt RP (2002) Constructing event trees for volcanic crises. Bull Volcan 64:3-20. doi:10. 1007/s004450100173

Pindyck RS (1991) Irreversibility, uncertainty, and investment. J Econ Lit 29:1110-1148

Reniers GLL, Audenaert A, Pauwels N, Soudan K (2011) Empirical validation of a real options theory based method for optimizing evacuation decisions within chemical plants. J Hazard Mater 186:779-787. doi:10.1016/j.jhazmat.2010.11.061

Van Stiphout T, Wiemer S, Marzocchi W (2010) Are short-term evacuations warranted? Case of the 2009 L'Aquila earthquake. Geophys Res Lett 37 doi:10.1029/2009g1042352

Yu H, Chen J-G (2011) The activating model of contingency plans within disruptive incidents. In: Service Systems and Service Management (ICSSSM), 8th international conference on digital object identifier, Tianjin, 2011. IEEE, pp 1-5 doi:10.1109/ICSSSM.2011.5959506 